\title{
New Experimental Technique for Nodularity and Mg Fading Control in Compacted Graphite Iron Production on Laboratory Scale
}

\author{
JUAN CARLOS HERNANDO, BJÖRN DOMEIJ, DANIEL GONZÁLEZ, \\ JOSÉ MANUEL AMIEVA, and ATTILA DIÓSZEGI
}

\begin{abstract}
The narrow production window for compacted graphite iron material (CGI) drastically reduces the possibilities to produce it in small batches outside an industrial environment. This fact hinders laboratory-scale investigations on CGI solidification. This work presents a solution to that issue by introducing an experimental technique to produce graphitic cast iron of the main three families. Samples of a base hypereutectic spheroidal graphite iron (SGI) were re-melted in a resistance furnace under $\mathrm{Ar}$ atmosphere. Varying the holding time at $1723 \mathrm{~K}\left(1450{ }^{\circ} \mathrm{C}\right)$, graphitic irons ranging from spheroidal to lamellar were produced. Characterization of the graphite morphology evolution, in terms of nodularity as a function of holding time, is presented. The nodularity decay for the SGI region suggests a linear correlation with the holding time. In the CGI region, nodularity deterioration shows a slower rate, concluding with the sudden appearance of lamellar graphite. The fading process of magnesium, showing agreement with previous researchers, is described by means of empirical relations as a function of holding time and nodularity. The results on nodularity fade and number of nodules per unit area fade suggest that both phenomena occur simultaneously during the fading process of magnesium.
\end{abstract}

DOI: $10.1007 / \mathrm{s} 11661-017-4315-3$

(C) The Author(s) 2017. This article is an open access publication

\section{INTRODUCTION}

ONE of the critical issues of CGI and SGI production is the control of nucleation and growth mechanisms of graphite. ${ }^{[1]}$ The nucleation of graphite is commonly assumed heterogeneous in main graphite nucleation theories. ${ }^{[2]}$ This concept assumes that graphite particles nucleate on a pre-existing inclusion in the liquid. ${ }^{[3-7]} \mathrm{In}$ the case of lamellar graphite iron (LGI), these inclusions are complex sulfides $(\mathrm{Mn}, \mathrm{X}) \mathrm{S}$ that at the same time have nucleated on complex oxides of $\mathrm{Al}, \mathrm{Si}, \mathrm{Zr}, \mathrm{Mg}$, and $\mathrm{Ti}^{[3-5]}$ On the other hand, graphite in SGI and CGI is observed to have similar nuclei, formed by complex $\mathrm{Mg}$ silicates $\left(\mathrm{MgO} \mathrm{SiO}_{2}\right)$ which are nucleated on the external layer of MgS and CaS sulfides. ${ }^{[6]}$ The subsequent growth of graphite nuclei is primarily affected by two factors: the presence of surface-active impurities in the melt, and the cooling rate during solidification of the alloy. ${ }^{[1]}$ The

JUAN CARLOS HERNANDO, BJÖRN DOMEIJ, DANIEL GONZÁLEZ, JOSÉ MANUEL AMIEVA, and ATTILA DIÓSZEGI are with the Department of Materials and Manufacturing, Jönköping University, Gjuterigatan 5, 551 11, Jönköping, Sweden. Contact e-mail: Juan-Carlos.Hernando@ju.se

Manuscript submitted March 28, 2017.

Article published online September 14, 2017 effect of the latter is widely accepted; higher cooling rates promote the formation of SGI. The influence of impurities can be divided into two categories: (a) reactive impurities leading towards a SGI transition such as $\mathrm{Mg}, \mathrm{Ce}, \mathrm{Ca}, \mathrm{Y}$, and $\mathrm{La}$, called compacting or spheroidizing elements; and (b) surface-active impurities favoring lamellar graphite formation, such as $\mathrm{S}, \mathrm{O}, \mathrm{Al}$, $\mathrm{Ti}, \mathrm{As}, \mathrm{Bi}, \mathrm{Te}, \mathrm{Pb}$, and $\mathrm{Sb}$, called anti-compacting or anti-spheroidizing elements. ${ }^{[1]}$ The presence of these impurities influences the predominant growth direction of graphite. ${ }^{[8,9]}$ In the case of LGI, dominant growth occurs along the A-axis, while in SGI it happens along the $\mathrm{C}$-axis. $\mathrm{CGI}$ is in an intermediate situation since dominant growth direction changes continuously between the $\mathrm{A}$-axis and the $\mathrm{C}$-axis. ${ }^{[8,9]}$ The surface-active impurities are absorbed in the prismatic face of the hexagonal graphite lattice, creating a non-faceted interface, that requires low driving forces to grow, i.e., low undercooling, like in the case of LGI, while for SGI the faceted interface requires larger undercooling to grow. ${ }^{[2,4,7]}$ Previous experiments show that a completely impurities-free melt would solidify as SGI, indicating that the preferential shape for graphite is spheroids in the total absence of active surface impurities. ${ }^{[9]}$ However, the amount of impurities needed to promote the formation of LGI is extremely low, ${ }^{[2]}$ being the presence 
of $\mathrm{O}$ and $\mathrm{S}$ the most detrimental to that effect due to their strong tendency to reduce the surface energy. ${ }^{[1,8,9]}$ The presence of dissolved oxygen in the melt has been shown to have a direct impact in the nodularity of the iron. ${ }^{[10-12]}$ The formation of CGI and SGI, therefore, requires the reduction of the amount of dissolved $\mathrm{O}$ and $\mathrm{S}$ that are regularly present in the materials used as base alloys. The practical way to achieve this reduction is by the addition of specific elements reacting and combining with $\mathrm{O}$ and $\mathrm{S}$ and hence cleaning the melt from these impurities, in a process called nodularization. The main element used for this purpose is $\mathrm{Mg}$, even though some other elements like Ce or a RE mixture are also used with the same objective. ${ }^{[2,13,14]} \mathrm{Mg}$ added to the melt, usually as FeSiMg, is used to combine most of the $\mathrm{O}$ dissolved in the melt by formation of oxides. The presence of dissolved $\mathrm{S}$ is also eliminated by $\mathrm{Mg}$, producing $\mathrm{MgS}$. High levels of $\mathrm{S}$ thus represent a complication for this purpose, since part of the $\mathrm{Mg}$ intended for $\mathrm{O}$ neutralization will be consumed by $\mathrm{S}$ making it a matter of great importance to have a close control on this process. ${ }^{[12,15]}$ Residual $\mathrm{Mg}$ contents of $0.006 \mathrm{wt}$ pct are reported as the lower limit to produce CGI, while the upper limit is around $0.01 \mathrm{wt}$ pet residual $\mathrm{Mg}{ }^{[2]}$ To ensure a full spheroidization in SGI production, the measured residual $\mathrm{Mg}$ has to be between 0.02 and $0.06 \mathrm{Mg}$ wt pct. ${ }^{[14]}$ These boundaries will change as a function of the amount of total impurities, shifting the CGI region towards higher $\mathrm{Mg}$ content in case of high presence of $\mathrm{O}$ and $\mathrm{S}$. There are two main problems associated with the nodularization treatment in CGI and SGI production. The first one is to achieve the intended nodularity with the treatment at the end of the solidification. The region between LGI and CGI is especially complex, since there is an abrupt transition from CGI to LGI as a function of $\mathrm{Mg}$ content, complicating CGI production. ${ }^{[13]}$ In the case of SGI production, high additions of $\mathrm{Mg}$ are reported to attenuate the effect after a critical level, reaching an asymptotic level for nodularity. ${ }^{[13]}$ The second problem is the disappearance of the effect of this nodularization treatment over time. This occurs when the treated iron is held at elevated temperatures. The practical solution is therefore usually to minimize the time between nodularization treatment and pouring. Previous works have studied the fading phenomenon in SGI and CGI production, studying its relation to cooling curves and the residual $\mathrm{Mg}$ after different holding times. ${ }^{[16-21]}$ All these technological difficulties severely hamper laboratory investigations in CGI, and to some extent also in SGI, which in turn limits the understanding of complex problems occurring during their solidification that often lead to defect formation. The present work, therefore, reports an accurate and reliable experimental technique, which enables controlled laboratory-scale production of cast irons, with controlled graphite morphology ranging from SGI to LGI. A re-melting experimental procedure has been designed to control the process of solidification of a base SGI material and adjust its final nodularity by controlling the holding time as the experimental variable. Tools to evaluate the nodularity and the $\mathrm{Mg}$ fading process during the reversion process of SGI are presented, including empirical equations to predict the resulting nodularity at the end of the solidification process for both SGI and CGI production regions.

\section{EXPERIMENTAL PROCEDURE}

\section{A. Base Material}

The base material is designed to meet two purposes: being able to produce iron of the three main families at the end of the solidification, and enabling the study of the fading process of $\mathrm{Mg}$ after the experimental process. The nodularization treatment is performed with FeSiMg using the tundish ladle method while inoculation is added in-stream during the pouring process. Optical emission spectrometry (OES) of a rapidly solidified coin produced immediately before the pouring process of the base SGI shows the following chemical composition, displayed in Table I.

The base alloy is cast in two furan sand molds, containing 25 open cylindrical cavities of $50 \mathrm{~mm}$ diameter and $300 \mathrm{~mm}$ in height. The sand mold is produced by sand printing and designed to promote a bottom-to-top filling of the mold cavities. The two molds are poured from the same ladle in a sequential operation to minimize the fading of nodularization treatment and the decarburization of the alloy. The cylinders of the base material are then machined to cylinders of $38 \mathrm{~mm}$ diameter with a weight of $400 \pm 0.5 \mathrm{~g}$ which yields an approximate height of 42 $\mathrm{mm}$.

\section{B. Experimental Equipment}

The experimental equipment for the re-melting process is very similar to the equipment used on some previous investigations on LGI solidification ${ }^{[22-24]}$; slight modifications of the equipment enabled its application to SGI and CGI. The experimental equipment consists of a programable resistance furnace where a specimen of the base material is re-melted. The specimen is introduced into the furnace's chamber inside an $\mathrm{Al}_{2} \mathrm{O}_{3}$

Table I. Chemical Composition of the Base Alloy

\begin{tabular}{lccccccccc}
\hline Element & $\mathrm{C}$ & $\mathrm{Si}$ & $\mathrm{Mn}$ & $\mathrm{P}$ & $\mathrm{S}$ & $\mathrm{Cu}$ & $\mathrm{Sn}$ & $\mathrm{Mg}$ & $\mathrm{CE}$ \\
\hline Weight percent & 3.86 & 2.59 & 0.64 & 0.030 & 0.010 & 0.84 & 0.098 & 0.065 & 4.73 \\
\hline $\mathrm{CE}=\mathrm{C}+1 / 3(\mathrm{Si}+\mathrm{P})$. & & & & & & & & & \\
\hline
\end{tabular}


crucible and it is placed in the middle of the heating elements. The chamber is filled with a stable argon flow of $4 \mathrm{l} / \mathrm{min}$ to achieve a neutral atmosphere and preserve the chemical composition of the melt during the re-melting and subsequent holding time. The main objective is to slow down the fading process of $\mathrm{Mg}$ in order to study its evolution on a wider time range than in previous investigations. ${ }^{[17]}$ In this study, the argon intake is modified with respect to previous investigations, ${ }^{[22-24]}$ and it is now placed at the bottom part of the chamber, producing an ascending flow of argon during the process. Argon is vented from the chamber through the small outlets located in the upper lid, provoking a continuous flow of argon inside the chamber. In the experimental re-melting process, a complete absence of oxygen is not reached since the chamber is not sealed to the external atmosphere, but a reduction and stabilization of the amount of oxygen during the re-melting process and holding time for different experiments are achieved. The equipment is designed to allow thermal measurements during solidification in three different positions. Two type-S thermocouples can be located at the middle section of the specimen, and one on the external part of the crucible on the same section. The reported thermal data represent the values for the thermocouple located at the midpoint of the middle section of the cylinder.

\section{Re-melting Experiments}

The base SGI is re-melted in form of cylindrical samples in a thermal cycle of 75 minutes from room temperature to $1723 \mathrm{~K}\left(1450{ }^{\circ} \mathrm{C}\right)$, with the intention to re-melt any possible pre-existing nuclei and graphite particle, and held for different times at that temperature. This holding time, representing the fading time of $\mathrm{Mg}$, is the single experimental variable that is modified to achieve different nodularities in the experimental samples. After the holding time is completed, the furnace is shut down and then cooling process starts, leading to the solidification of the sample. When the temperature in the furnace reaches $1273 \mathrm{~K}\left(1000{ }^{\circ} \mathrm{C}\right)$, the argon flow is interrupted and the cooling to room temperature occurs under the absence of argon flow.

Table II reports the experimental series of re-melting experiments performed in this study, starting from a holding time of 0 minutes up to 140 minutes. At the end of the solidification process, the sample is sectioned approximately at its middle section, around $20 \mathrm{~mm}$ from the bottom end. Samples are mounted in thermosetting resin and ground with $\mathrm{SiC}$ papers of different granulometry from a grit size of P80 (FEPA) to P2000 (FEPA) to subsequently start a mechanical polishing process with solutions containing diamond particles of 3 and $1 \mu \mathrm{m}$ applied on satin woven acetate and short synthetic nap clothes correspondingly. A good graphite retention is achieved after this process, ${ }^{[25]}$ but some graphite particles are partially covered by ferrite and could lead to a wrong interpretation. To solve this problem, an additional polishing step with an oxide slurry is manually applied for graphite characterization.

\section{Quenching Experiments}

A series of quenching experiments is additionally performed to analyze the chemical composition of the melt after the re-melting process and before the start of the solidification process after different holding times, see Table III. The sample is re-melted at $1723 \mathrm{~K}$ $\left(1450{ }^{\circ} \mathrm{C}\right)$ and held the correspondent time, but immediately after the end of the holding time, the sample is quenched into water to promote a white solidification and avoid graphite precipitation. This experimental series provides samples suitable for OES after a manual grinding process. One sample per holding time is produced.

\section{E. Graphite Characterization}

Several shape factors have been used for graphite characterization in last decades, such as roundness, sphericity, compactness, or circularity. ${ }^{[26-28]}$ This study characterizes the graphite evolution using the concept of nodularity explained in ISO 16112:2006(E) ${ }^{[29]}$ and E2567 - 16a from ASTM,${ }^{[30]}$ the standards with a wider application among cast iron users and industry. According to both standards, microstructural features smaller than $10 \mu \mathrm{m}$ are considered as microporosities, defects due to sample preparation or particles that should be excluded from graphite analysis. Graphite particles in contact with the limits of the image are not considered in the analysis. Nodularity characterization is based on the concept of roundness which is calculated for each graphite particles as follows:

$$
\text { Roundness }=\frac{A}{A_{\text {circle }}}=\frac{4}{\pi} * \frac{A}{l_{\max }^{2}}
$$

where $A$ is the area of the particle and $A_{\text {circle }}$ is the area of a circle with a diameter equal to the maximum distance between two boundary points of the particle, $l_{\max }$. The measurement of these two features, $A_{\text {circle }}$ and $l_{\max }$, is carried out with the OLYMPUS Stream Motion Desktop software 1.9.1. A graphite nodule consists of any graphite particle that fulfills both minima required size i.e., $>10 \mu \mathrm{m}$ and roundness factor $>0.625$ according to ISO standard and a

Table II. Overview of the Re-Melting Experiments Series

\begin{tabular}{lccccccccccccccc}
\hline Sample ID & H0 & H10 & H20 & H30 & H40 & H50 & H60 & H70 & H80 & H90 & H100 & H110 & H120 & H130 & H140 \\
\hline Holding time (min) & 0 & 10 & 20 & 30 & 40 & 50 & 60 & 70 & 80 & 90 & 100 & 110 & 120 & 130 & 140 \\
Repetitions & 2 & 4 & 3 & 3 & 3 & 2 & 3 & 2 & 3 & 2 & 3 & 2 & 2 & 3 & 3 \\
\hline
\end{tabular}


Table III. Overview of the Quenching Experiments Series

\begin{tabular}{lcccccc}
\hline Sample ID & Q0 & Q10 & Q20 & Q30 & Q60 & Q110 \\
\hline Holding time (min) & 0 & 10 & 20 & 30 & 60 & 110 \\
\hline
\end{tabular}

recommended roundness factor of $>0.6$ by ASTM standard. While ASTM standard only accounts for nodular graphite particles when calculating percent nodularity, ISO standard also considers intermediate graphite particles (forms IV and V) with roundness factor 0.525 to 0.625 , as follows:

$$
\begin{aligned}
\text { Percent Nodularity }= & 100 *\left(\sum A_{\text {nodules }}+0.5 * \sum A_{\text {intermdiates }}\right) / \\
& \sum A_{\text {all graphite particles }}
\end{aligned}
$$

It has been demonstrated in the literature ${ }^{[27]}$ that a minimum pixel size cannot be used for general cases, and its selection depends on the dimensions of graphite particles present in the sample. In this case, a preliminary analysis of the microstructures reveals a large graphite particle size, enabling the use of a low magnification, resulting in a pixel side length of $1.081 \mu \mathrm{m}$. This pixel size allows to characterize a much larger surface area than required in the norms, using a minimum of 40 micrographs for each specimen, representing a minimum area of $137 \mathrm{~mm}^{2}$ for each specimen, improving result soundness.

\section{RESULTS AND DISCUSSION}

\section{A. Effect of Holding Time on Nodularity and Graphite Particle Density}

As introduced in previous sections, the main objective of this paper is to control the nodularity variation by controlling the holding time, in order to describe the transition from SGI, to CGI and later to LGI. The analysis of the base material, as starting material used for the experimental series, shows a fully nodular iron with a nodularity of 96 pct. The high nodularity measured and the high residual $\mathrm{Mg}$ present in the base material makes it appropriate for the purpose of this work.

Micrographs of the samples resulting from re-melting experiments, from $\mathrm{H} 0$ to $\mathrm{H} 140$, are collected in Figure 1. It can be observed in the micrographs that the number of graphite nodules decreases as the volume fraction of compacted graphite increases with increasing holding time. While transition between SGI and CGI occurs gradually, the transition between CGI and LGI occurs suddenly, as reported in the literature ${ }^{[13]}$ The appearance of lamellar graphite occurs after 130 minutes of holding time, resulting in a successful value for experimental purposes, allowing the controlled production of a wide range of graphite shapes using this experimental technique.
The nodularity analysis of the samples from the re-melting experiments shows clearly how nodularity drops with increasing holding time. In Figure 2, one can deduce a linear decay on the first region of the curve, from 0 to 50 minutes of holding time. Whilst the rate of deterioration of nodularity from 60 to 120 minutes slows down, belonging to CGI irons as the nodularity values drop below the 20 pct, the upper barrier required for CGI material. ${ }^{[29]}$ After 130 minutes of holding time, lamellar graphite suddenly appears in the sample. The presence of graphite of type I and II, corresponding to LGI, according to ISO $945,{ }^{[31]}$ makes the characterization of nodularity for those samples inappropriate. For that reason, samples from $\mathrm{H} 130$ and $\mathrm{H} 140$, showing lamellar graphite particles, are not characterized in terms of nodularity.

In a previous investigation, nodularity fade and nodule count fade were treated as independent phenomena with an interrelated occurrence. ${ }^{[18]}$ Results of the current investigation show that nodularity and number of nodules per unit area exhibit a similar correlation with the holding time. Both phenomena seem to occur simultaneously according to Figures 2 and 3(a). The number of nodules per unit area shows the transition towards CGI with increasing holding time, process governed mainly by the residual $\mathrm{Mg}$, since the cooling conditions can be considered similar for all experiments. At the same time, data in Figure 3(b) reveal that the number of vermicular graphite per unit area follows a linear trend with holding time, while the number of intermediate particles per unit area does not vary significantly with holding time, Figure 3(a).

\section{B. Effect of Holding Time on Cooling Curves}

The shape of a cooling curve can be affected by many variables and a large number of correlations between them. ${ }^{[32,33]}$ Despite all those variables at play, it is widely accepted a general specific behavior for each graphitic iron family. ${ }^{2]}$ In this work, all variables are reduced to one, the holding time, and the change in this variable is affecting the residual $\mathrm{Mg}$ present in the melt during the solidification. Therefore, from the analysis of the cooling curves, we will be able to observe the relation between the shape of the cooling curve and the residual $\mathrm{Mg}$ content and the different graphite shapes present in the microstructure.

The cooling curves from the re-melting experiments, Figure 4, can be clearly divided into three different groups. These groups can be related to the presence of a different type of graphite shape in the final microstructure. The first group consists of the cooling curves belonging to $\mathrm{H} 10$ and $\mathrm{H} 20$, showing the typical shape of 

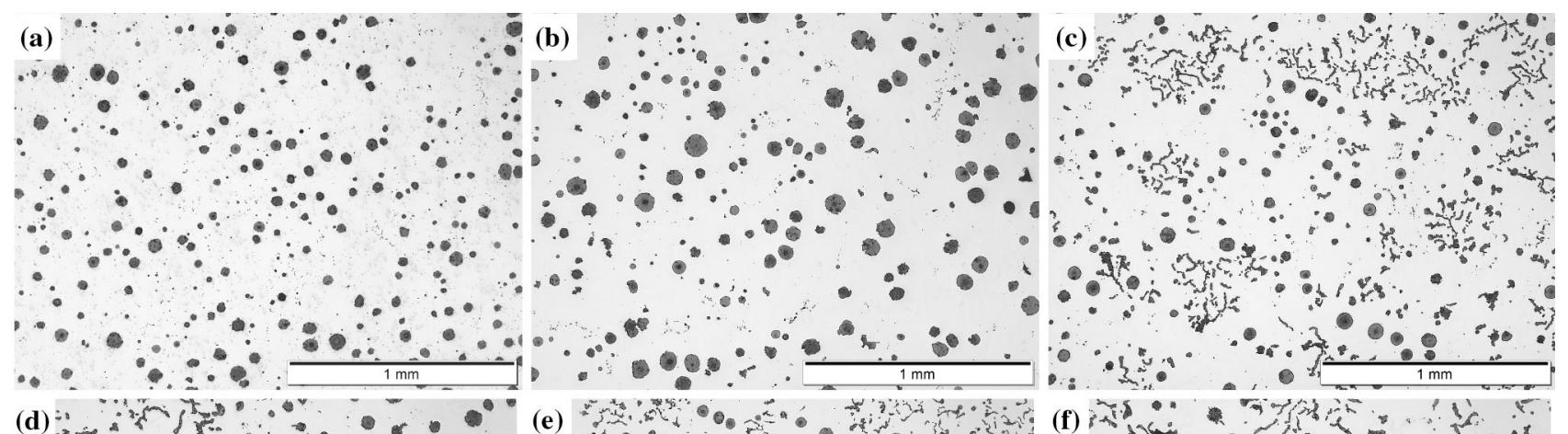

(d)

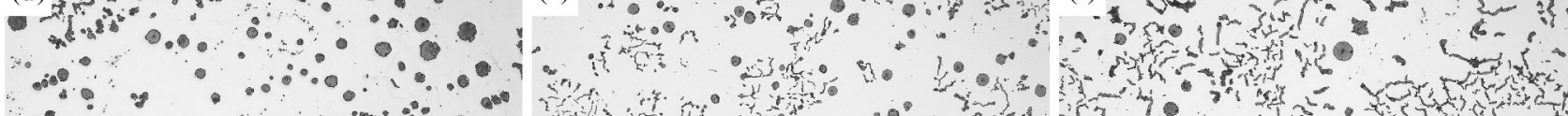

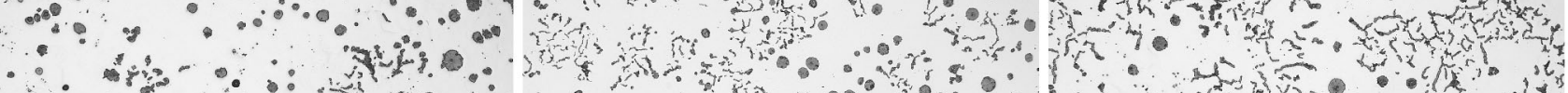

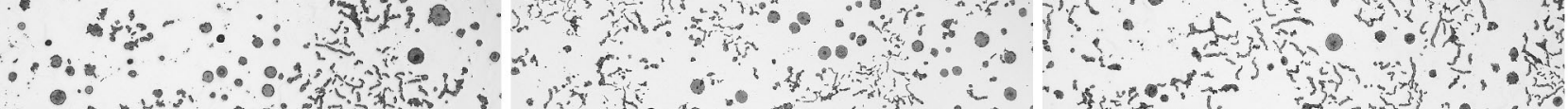

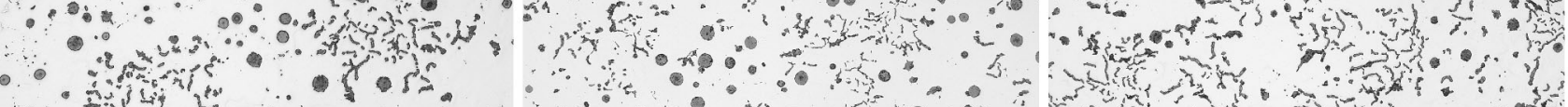

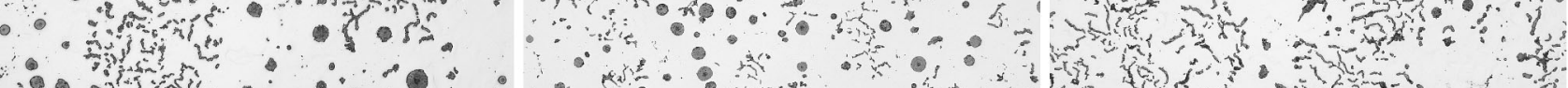

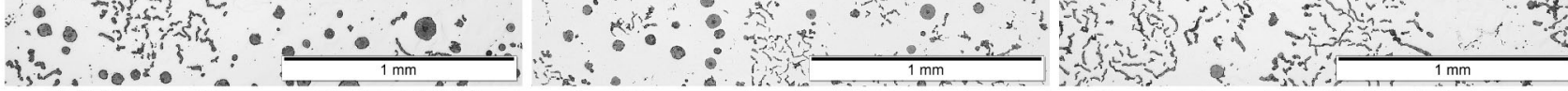

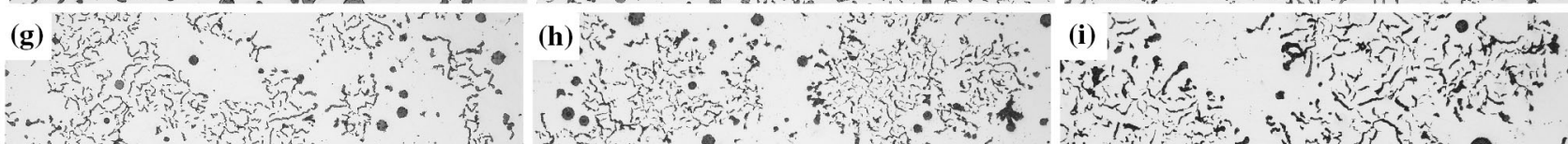
- w o Q

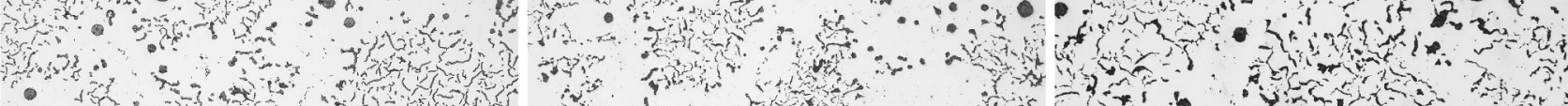
and $\therefore$ ond

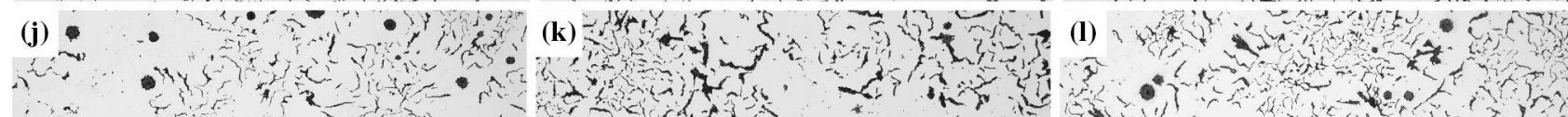
(1) (m) $\quad \frac{1}{10} \frac{1}{1 \mathrm{~mm}}$ (m) 3 (n)

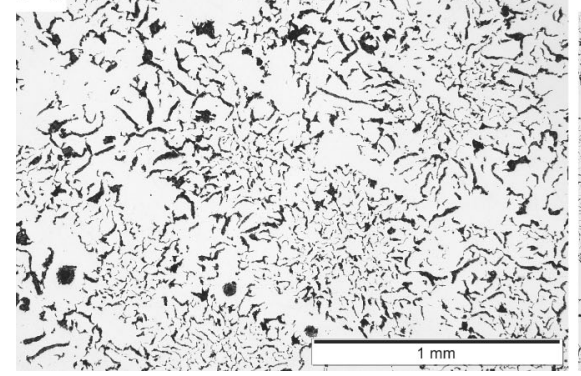

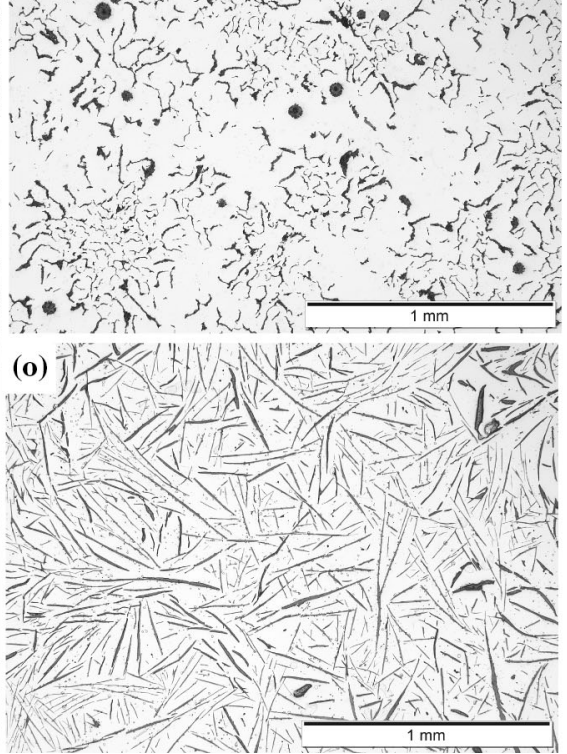

Fig. 1-Micrographs of the material resulting from the re-melting experiments: (a) 0, (b) 10, (c) 20, (d) 30, (e) 40, (f) 50, (g) 60, (h) 70, (i) 80, (j) 90, $(k) 100(l) 110,(m) 120,(n) 130$, and $(o) 140 \mathrm{~min}$ of holding time. 
an SGI solidification reported in the literature for sand cups, ${ }^{[34]}$ with a high undercooling and low recalescence rate. In these cases, the nodularity values are 86.48 and 70.50 pct, corresponding to an SGI grade. When the presence of compacted graphite starts to be significant in the microstructure, even if the final nodularity values yield to values over $20 \mathrm{pct}$, both the undercooling and the recalescence increase. Worth to mention is the considerable increase in the recalescence rate, as can be seen in the cooling curve of $\mathrm{H} 40$, which final nodularity yields $41.17 \mathrm{pct}$, far from the CGI values. This behavior is repeated for $\mathrm{H} 60, \mathrm{H} 80$, and $\mathrm{H} 100$ samples with nodularity values of $14.32,10.49$, and 5.23 pct, all within the CGI range according to ISO standard showing accordance to literature. ${ }^{[34]}$ The last group of cooling curves reflects the presence of lamellar graphite

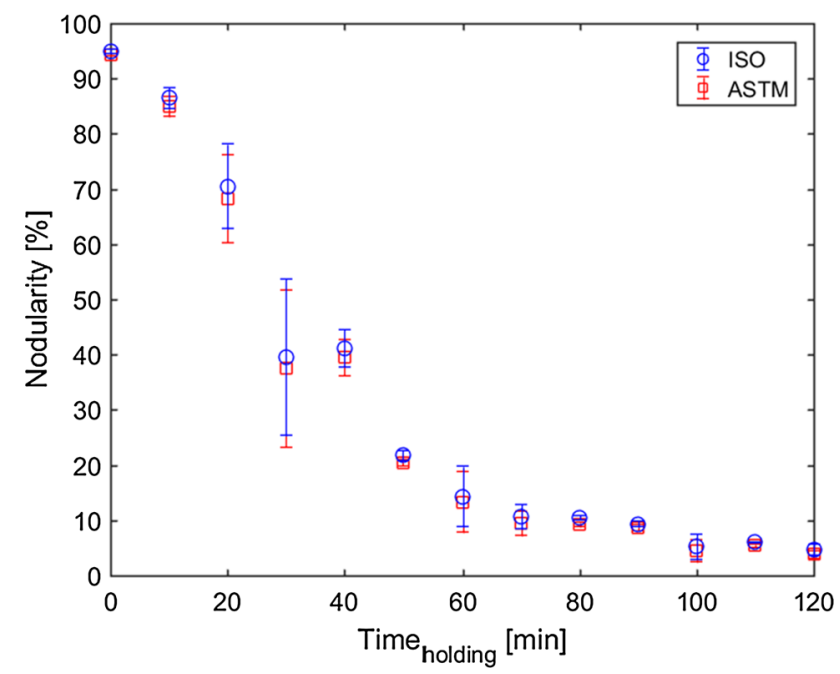

Fig. 2-Nodularity evolution as a function of holding time. Circles represent nodularity values according to ISO 16112 standard, and squares represent nodularity values according to E2567 ASTM standard. Error bars represent the 95 percent confidence interval.

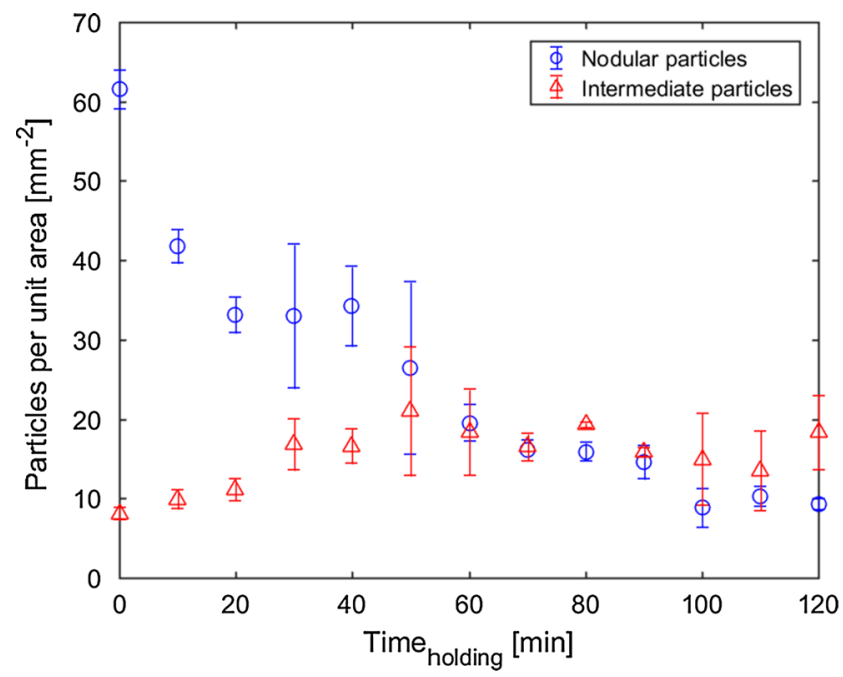

(a) in the microstructure, H130, and H140. The low undercooling and intermediate recalescence rate are commonly found in LGI literature.

\section{Effect of Holding Time on Chemical Composition}

The quenching experiments made possible to measure the chemical composition by OES and thus to find possible changes in the chemical composition during holding time. From the results in Table IV, it can be observed that the re-melting experimental process under the argon atmosphere is stable and the sample does not suffer strong variations in the chemical composition. The main elements affecting cast iron solidification like $\mathrm{C}, \mathrm{Si}, \mathrm{S}, \mathrm{P}, \mathrm{Mn}, \mathrm{Cu}$, and $\mathrm{Sn}$ show a stable behavior over the holding time. Only $\mathrm{Mg}$ is affected by holding time.

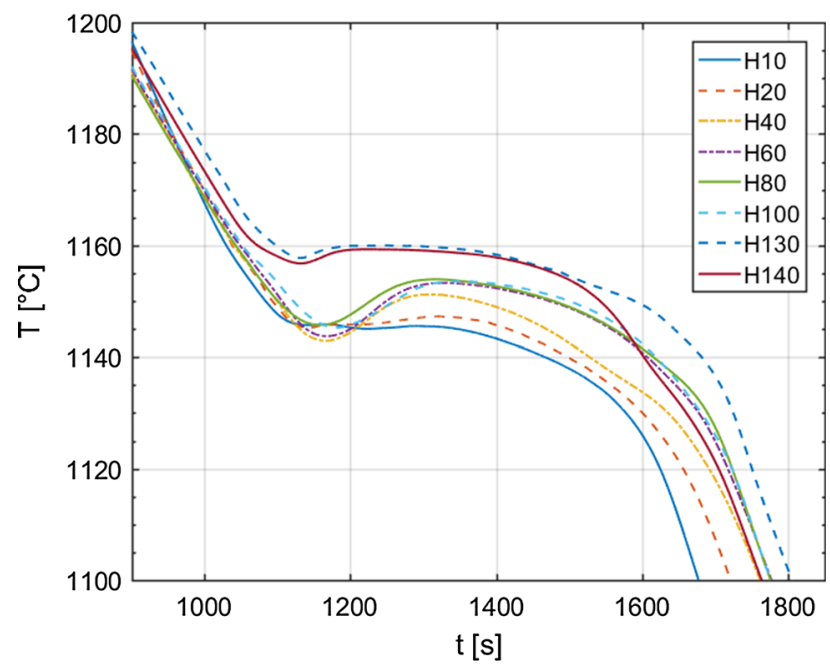

Fig. 4-Representative cooling curves from the re-melting experiments.

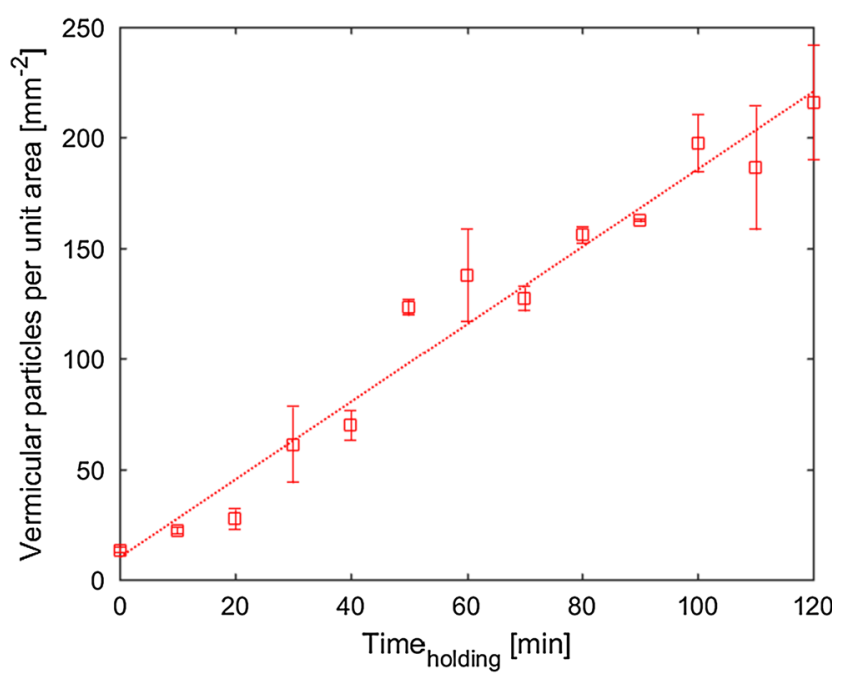

(b)

Fig. 3- (a) Number of nodules and intermediate particles and (b) number of vermicular particles per unit as a function of holding time. Error bars represent the 95 percent confidence interval. 
Table IV. Chemical Composition in Weight Percent After Quenching Experiments

\begin{tabular}{lccccccr}
\hline Sample & $\mathrm{C}$ & $\mathrm{Si}$ & $\mathrm{Mn}$ & $\mathrm{P}$ & $\mathrm{S}$ & $\mathrm{Cu}$ & $\mathrm{Sn}$ \\
\hline Base SGI & 3.86 & 2.59 & 0.64 & 0.030 & 0.010 & 0.84 & 0.098 \\
Q0 & 3.51 & 2.64 & 0.66 & 0.035 & 0.008 & 0.84 & 0.096 \\
Q10 & 3.75 & 2.52 & 0.70 & 0.036 & 0.011 & 0.89 & 0.123 \\
Q20 & 3.52 & 2.69 & 0.70 & 0.035 & 0.009 & 0.86 & 0.105 \\
Q30 & 3.67 & 2.66 & 0.65 & 0.035 & 0.008 & 0.83 & 0.095 \\
Q60 & 3.83 & 2.56 & 0.65 & 0.037 & 0.009 & 0.84 & 0.093 \\
Q110 & 3.94 & 2.59 & 0.66 & 0.033 & 0.010 & 0.84 & 0.093 \\
\hline
\end{tabular}

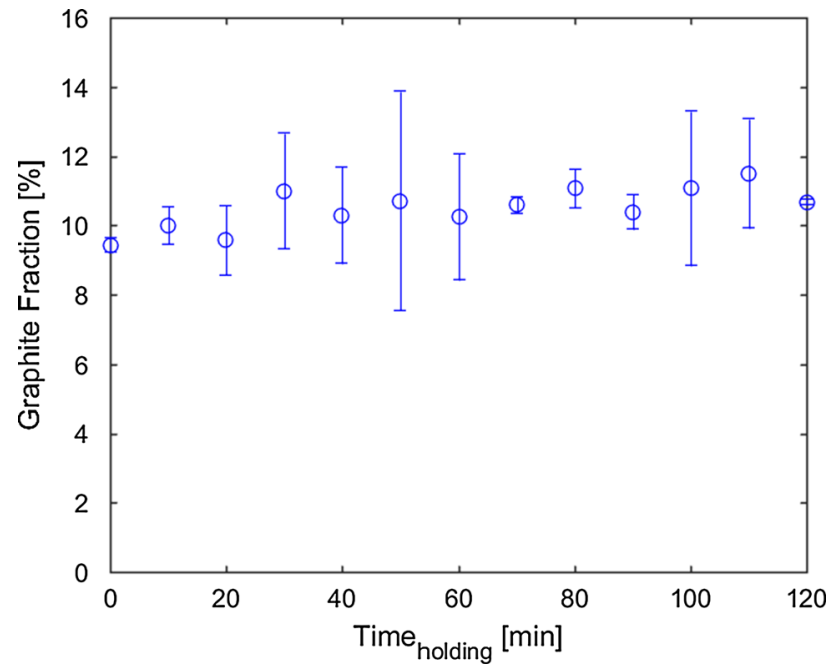

Fig. 5- Graphite fraction measured after re-melting experiments.

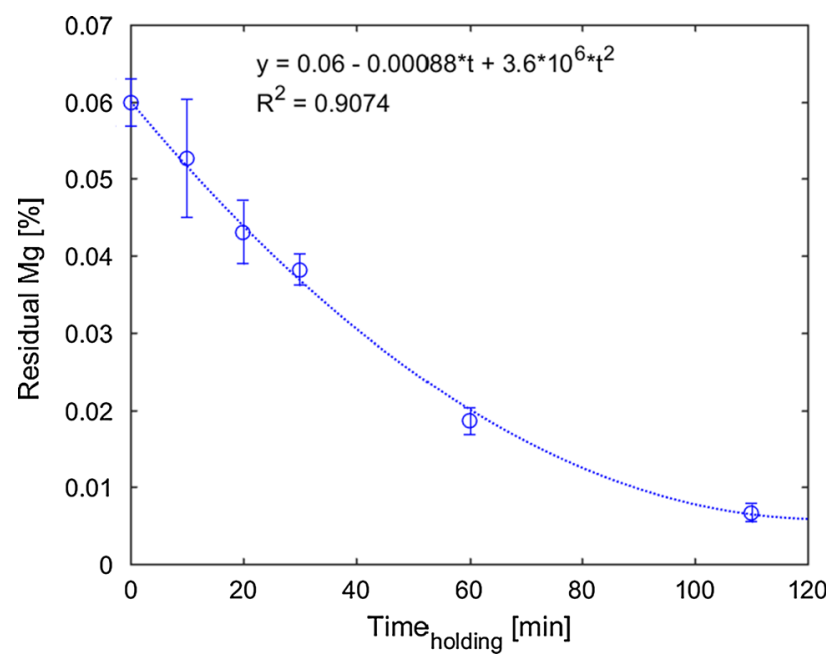

Fig. 6-Residual Magnesium content as a function of holding time. Error bars represent the 95 percent confidence interval.

In the case of carbon, it could be expected a certain decarburization after holding the melt at $1723 \mathrm{~K}$ $\left(1450{ }^{\circ} \mathrm{C}\right)$ for long times, but the Ar-rich atmosphere inside the chamber of the furnace drastically reduces the rate of this process. Results on carbon composition from Table IV, together with graphite volume fraction, shown in Figure 5, measured at room temperature after re-melting experiments show that carbon is not fading during the experimental process.

\section{Effect of Holding Time on Residual and Free Magnesium}

Holding time exhibits a clear influence on the evolution of residual magnesium that relates to the fading process, Figure 6. $\mathrm{Mg}$ is lost due to its high vapor pressure at this temperature and reaction with the small amount of oxygen present inside the chamber during the re-melting process and holding time at $1723 \mathrm{~K}$ $\left(1450{ }^{\circ} \mathrm{C}\right)$. During the reversion from SGI to CGI, occurring during the re-melting process, $\mathrm{Mg}$ residual content shows a polynomial relation with time in minutes, Eq. [3].

$$
\text { Residual Mg (wt pct) }=0.06-0.00088 t+3.6 * 10^{-6} t^{2}
$$

for $0<t<110$, where time is in minutes.

From the available literature, the fading rate varies strongly between different studies focusing either only in the CGI or SGI region. Only a holistic study covering both regions can monitor the whole process of fading. Several authors previously reported diverse experimental expressions for the fading process of $\mathrm{Mg}$ at similar temperatures for SGI and CGI production. In the case of the SGI region, a previous work studied the effect of holding the iron inside an 8 tons' channel induction furnace under argon atmosphere, it is reported an average $\mathrm{Mg}$ fading rate of $0.002 \mathrm{wt} \mathrm{pct} / \mathrm{h} \cdot{ }^{[17]}$ For the case of CGI, the effect of holding time on residual $\mathrm{Mg}$ shows a relatively low fading rate at short times, showing a decay from 0.018 to $0.015 \mathrm{wt}$ pet $\mathrm{Mg}$ after 3 minutes while the rate increases for a longer time, consuming most of $\mathrm{Mg}$ content, remaining only $0.001 \mathrm{wt}$ pet $\mathrm{Mg}$ after 7 minutes of holding time. ${ }^{[20]}$ A similar expression to Eq. [3] for residual $\mathrm{Mg}$ is reported only for the CGI region, valid only for an initial starting $\mathrm{Mg}$ content of $0.018 \mathrm{wt}$ pet and for time up to 7 minutes of holding time.

Another study that tries to cover the whole range of reversion reported a similar expression for fading time, but values of residual $\mathrm{Mg}$ are significantly lower to the ones found in this investigation. ${ }^{[18]}$ Starting with a similar Mg content, the fading occurs more rapidly, due to the larger surface area of melt exposed to the atmosphere together with the absence of a continuous gas flow protecting the melt. It is reported only a 0.023 
wt pet $\mathrm{Mg}$ after 30 minutes of holding time and remaining only $0.002 \mathrm{wt}$ pct $\mathrm{Mg}$ after 90 minutes of holding time.

The expression derived from the experimental data here reported covers both the SGI and CGI regions and extends its validity for times up to 110 minutes. This fact demonstrates that Ar-rich atmosphere is an effective way to slow down the fading process of $\mathrm{Mg}$ and therefore to extend the process window for SGI and CGI production.

The amount of $\mathrm{Mg}$ measured by spectrometry reflects the total $\mathrm{Mg}$ present in the sample, i.e., the residual magnesium, including the free $\mathrm{Mg}$ dissolved in the melt plus the $\mathrm{Mg}$ which is combined with other elements. $\mathrm{Mg}$ and $\mathrm{S}$ are expected to combine according to Eq. [4]. ${ }^{[15]}$ Hence, a rough estimation of free $\mathrm{Mg}\left(w_{\mathrm{Mg} \text {,free }}\right)$ can be done by subtracting from the total $\mathrm{Mg}$, i.e., residual magnesium $\left(w_{\mathrm{Mg}}\right)$ that amount of magnesium combined with Sulfur ( $\left.w_{S}\right)$ by means of Eq. [4] where $\mathrm{M}_{\mathrm{Mg}}$ and $\mathrm{M}_{\mathrm{S}}$ represent the atomic weights of $\mathrm{Mg}(24.305 \mathrm{~g} / \mathrm{mol})$ and $\mathrm{S}$ $(32.065 \mathrm{~g} / \mathrm{mol})$, respectively ${ }^{[15]}$ :

$$
\begin{gathered}
\mathrm{Mg}+\mathrm{S} \rightarrow \mathrm{MgS} \\
w_{\mathrm{Mg}, \text { free }}=w_{\mathrm{Mg}}-\frac{M_{\mathrm{Mg}}}{M_{\mathrm{S}}} * w_{S} .
\end{gathered}
$$

In the context of this work, free $\mathrm{Mg}$ is calculated for each set of values for $\mathrm{Mg}$ and $\mathrm{S}$ from Table IV, and promotes the understanding of $\mathrm{Mg}$ fading independently of $\mathrm{S}$ content. Thus, it allows the application of the results obtained in this study on irons with different $S$ contents, only dependent on the initial $\mathrm{Mg}$ content, which can be easily calculated after the nodularization treatment (Figure 7).

\section{E. Relation Between Magnesium Fading and Nodularity}

Dawson published a chart (Figure 8) that correlates residual $\mathrm{Mg}$ and nodularity for CGI and SGI castings

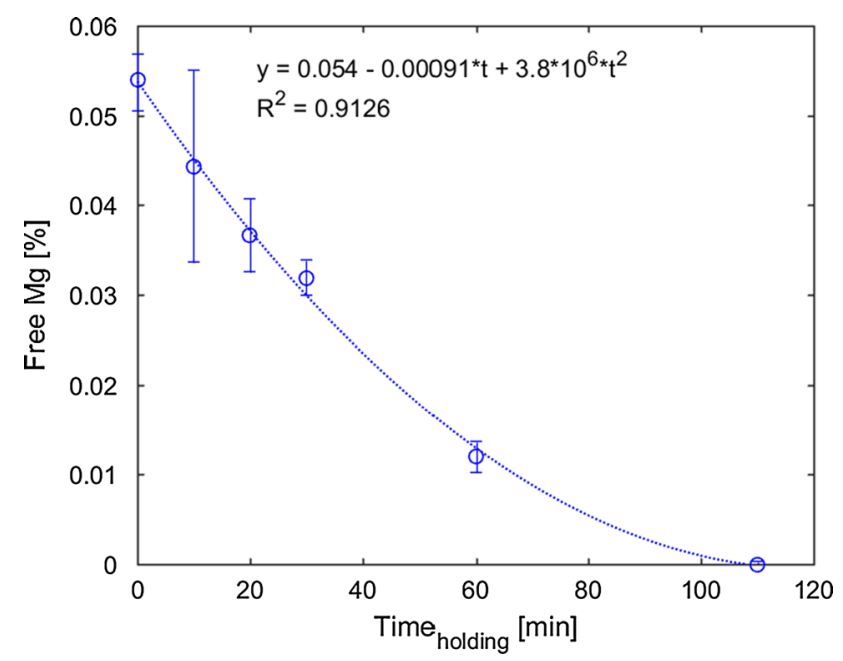

Fig. 7-Estimation of free Magnesium content as a function of holding time ${ }^{[15]}$ Error bars represent the 95 percent confidence interval. for 0.013 wt pet S. ${ }^{[13]}$ Establishing 0.006 wt pet $\mathrm{Mg}$ as lower limit for CGI before the sudden transition to LGI occurs, the higher limit for CGI production is set around 0.016 wt pet $\mathrm{Mg}$. In the same graph, the lower limit for production of SGI is set around 0.030 wt pet $\mathrm{Mg}$ when contents around $0.050 \mathrm{wt}$ pct $\mathrm{Mg}$ establish the upper limit above which increasing $\mathrm{Mg}$ concentration do not produce higher nodularities and could lead to defect formation. These values are however linked to several casting parameters like inoculation, oxygen and sulfur content, cooling conditions, etc. If these conditions change the curve shifts horizontally or vertically. An important consideration, though, is that the overall view of the regions of the graph where CGI and SGI are present resembles of a letter $\mathrm{S}$, giving this plot the name of "S-Curve."

The same appearance of a letter $\mathrm{S}$ is shown in this investigation when plotting nodularity against residual and free $\mathrm{Mg}$ contents in Figure 9. The mentioned figure from the literature ${ }^{[13]}$ and later attempts to

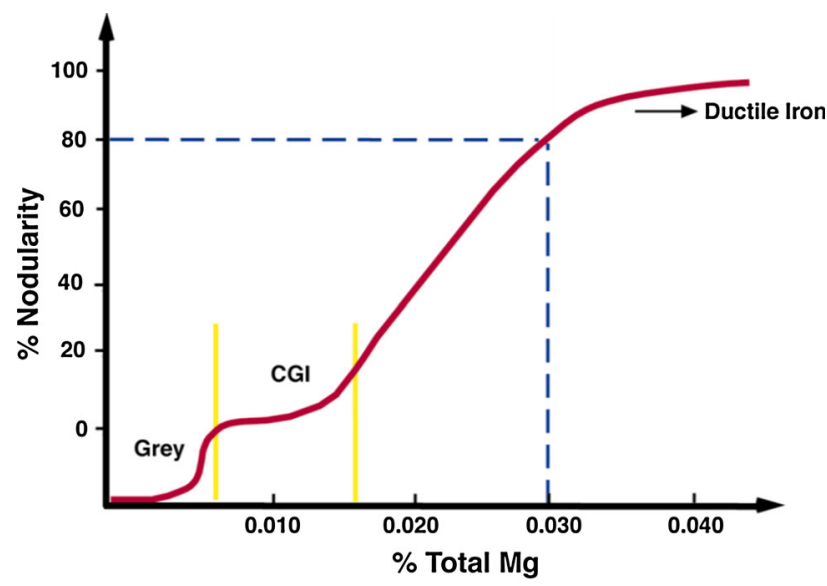

Fig. 8-Nodularity values as a function of residual Magnesium content according to Dawson. ${ }^{[13]}$ Reprinted with permission from SinterCast from reference, ${ }^{[35]}$ copyright (2014).

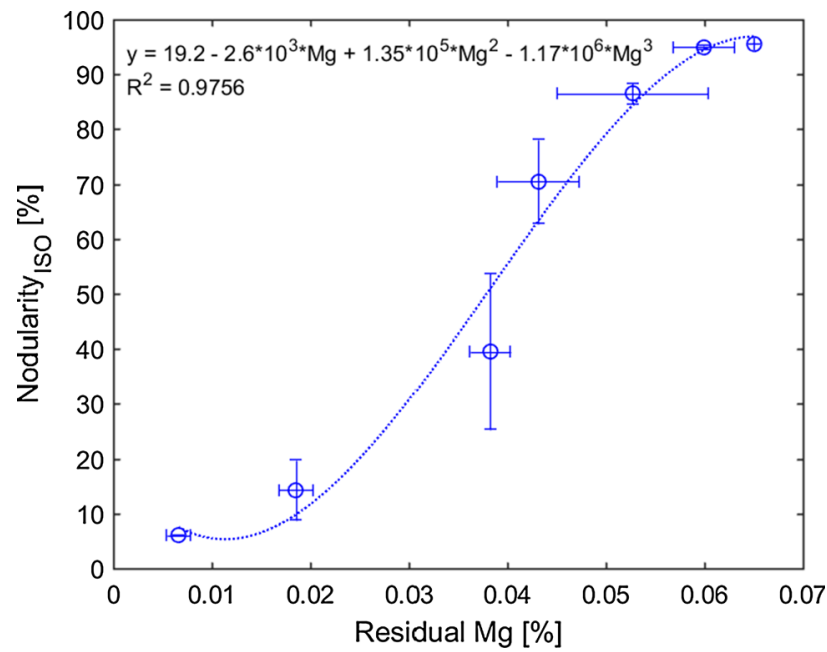

Fig. 9-Nodularity values, according ISO 16112 standard, as a function of residual Magnesium content. Error bars represent the 95 percent confidence interval. 


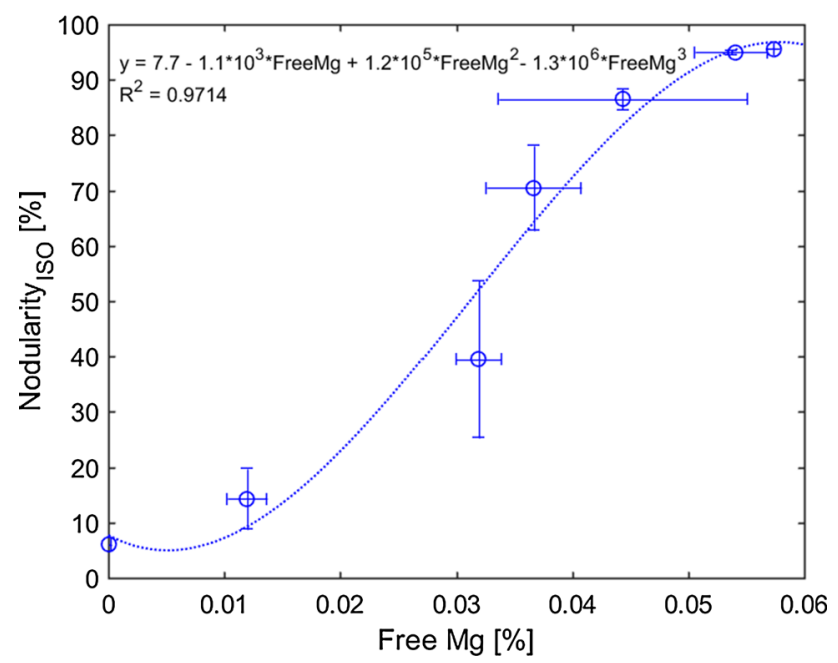

Fig. 10-Nodularity values, according ISO 16112 standard, as a function of free Magnesium content. Error bars represent the 95 percent confidence interval.

describe this relation between nodularity and $\mathrm{Mg}$ levels, ${ }^{[32]}$ never proposed a mathematical expression that could allow its modeling. In the present work, a third-order polynomial relation can be derived, Eq. [6], correlating nodularity according to ISO standard as a function of the residual $\mathrm{Mg}$ at the beginning of the solidification. The regions giving result to CGI and SGI can clearly be limited in Figure 9 by comparison with Figure 8. In this experimental procedure, the residual $\mathrm{Mg}$ limits for CGI production are 0.008 to $0.025 \mathrm{wt}$ pet of residual $\mathrm{Mg}$ and can be translated into the experimental parameter, the holding time, with Eq. [3]. The same observation can be done on the SGI region of the curve where an asymptotic behavior can be presumed for higher $\mathrm{Mg}$ values than $0.06 \mathrm{wt}$ pet of residual $\mathrm{Mg}$.

$$
\begin{aligned}
\text { Nodularity }_{\text {ISO }}(\text { wt pct })= & 19.2-2.60 * 10^{3} \mathrm{Mg}_{\text {res }} \\
& +1.35 * 10^{5} \mathrm{Mg}_{\text {res }}^{2}-1.17 * 10^{6} \mathrm{Mg}_{\text {res }}^{3}
\end{aligned}
$$

for $0.0066<\mathrm{Mg}<0.065$, where $\mathrm{Mg}$ is in wt pet.

In the case of free $\mathrm{Mg}$, the plot shows the same overall shape but it also shows how the fading of free $\mathrm{Mg}$ evolves allowing the estimation of free $\mathrm{Mg}$ and hence the resultant nodularity independent of S content. Figure 10 indicates that free $\mathrm{Mg}$ is very low after 110 minutes of holding time, which coincides with the transition into lamellar graphite morphology.

$$
\begin{aligned}
\text { Nodularity }_{\text {ISO }}(\text { wt pct })= & 7.7-1.10 * 10^{3} \mathrm{Mg}_{\text {free }} \\
& +1.2 * 10^{5} \mathrm{Mg}_{\text {free }}^{2}-1.3 * 10^{6} \mathrm{Mg}_{\text {free }}^{3}
\end{aligned}
$$

for $0<\mathrm{Mg}<0.057$, where $\mathrm{Mg}$ is in wt pet.

\section{CONCLUSIONS}

The new experimental technique was shown to be appropriate to control the production of irons with all kinds of graphitic morphologies from SGI to LGI. By modification of the holding time, the base SGI can be reversed to different grades of nodularity and into LGI iron. Modifications made in the experimental equipment, like the redesign of the argon intake, made possible the widening of production time window for production of SGI and CGI. Quenching experiments showed to be a successful tool to characterize the chemical evolution of the melt during the re-melting process by means of optical emission spectrometry. The most important conclusions based on the current results are the following:

- The first region of the curve relating nodularity and holding time shows a linear decay at short holding times. The CGI region shows a slower rate of reversion.

- The transition between SGI and CGI occurs gradually while transition between CGI and LGI is abrupt, in support of the conclusions of earlier researchers.

- Nodularity fade and number of nodules per unit area fade seem to occur simultaneously and not in an independent process as suggested by earlier works.

- From the analysis of the cooling curves from the re-melting experiments, we can conclude that all the samples with the presence of compacted graphite in the final microstructure show a similar behavior in the cooling curves regardless of the final nodularity values.

- Magnesium fading was successfully characterized in terms of the experimental variable. This fact opens the possibility to control and predict the final nodularity of the iron with accuracy using this experimental technique.

- The relation between nodularity and residual magnesium in the melt depicted on previous investigations has been proven to be valid for this new experimental process and a mathematical equation for its modeling is proposed.

The above conclusions show the robustness of the experimental technique developed in this work. This will allow future studies on CGI and SGI solidification through controlled laboratory experiments. Topics such as primary solidification, graphite degeneracy and solid state reaction modification are some of the open questions that may now be possible to study in laboratory controlled experiments by the application of this technique.

\section{ACKNOWLEDGMENTS}

This research was financed by VINNOVA, the Swedish Agency for Innovation, through the research projects CastDesign, grant number (2013-03303) and SPOFIC II, grant number (2013-04720). The projects, within the Swedish Casting Innovation Center (CIC), are a collaboration between Scania $\mathrm{CV} A B$, Volvo Powertrain Production Gjuteriet AB, SinterCast, Swer- 
ea SWECAST and Jönköping University. All support and participating personnel from the above institutions are gratefully acknowledged by the authors.

\section{OPEN ACCESS}

This article is distributed under the terms of the Creative Commons Attribution 4.0 International License (http://creativecommons.org/licenses/by/4.0/), which permits unrestricted use, distribution, and reproduction in any medium, provided you give appropriate credit to the original author(s) and the source, provide a link to the Creative Commons license, and indicate if changes were made.

\section{REFERENCES}

1. D.M. Stefanescu: Science and Engineering of Casting Solidification, 3rd ed., Springer, Berlin, 2015, pp 446-56.

2. M. König: Int. J. Cast Met. Res., 2010, vol. 23, pp. 185-92.

3. T. Skaland, Ø. Grong, and T. Grong: Metall. Trans. A, 1993, vol. 24, pp. 2321-45.

4. I. Riposan, M. Chisamera, S. Stan, and T. Skaland: Int. J. Cast Met. Res., 2003, vol. 16, pp. 105-11.

5. E. Moumeni, D.M. Stefanescu, N.S. Tiedje, P. Larrañaga, and J.H. Hattel: Metall. Mater. Trans. A., 2013, vol. 44, pp. 5134-46.

6. J. Tartera, N. Llorca-lsern, M. Marsal, and J.L. Rojas: Int. J. Cast Met. Res., 2003, vol. 16, pp. 131-35.

7. A.N. Roviglione and J.D. Hermida: Metall. Mater. Trans. B, 2004, vol. 35 , pp. 313-30.

8. S.V. Subramanian, D.A.R. Kay, and G.R. Purdy: AFS Trans., 1982, vol. 82, pp. 589-603.

9. D.D. Double and A. Hellawell: Acta Metall. Mater., 1995, vol. 43, pp. 2435-42.

10. J. Ekengård, A. Diószegi, and P.G. Jönsson: Int. J. Metalcast., 2016, vol. 10, pp. 500-15.

11. F. Mampaey, D. Habets, J. Plessers, and F. Seutens: Int. Found. Res., 2008, vol. 60, pp. 2-19.

12. F. Mampaey, D. Habets, J. Plessers, and F. Seutens: Int. J. Metalcast., 2010, vol. 4, pp. 25-43.

13. S. Dawson: Proceedings 106th AFS Casting Congress, Kansas City, USA, 2002
14. M. Holtzer, M. Górny and R. Dańko: Microstructure and Properties of Ductile Iron and Compacted Graphite Iron Castings. 1st ed., Springer, New York, 2015, pp. 15-113.

15. R. Suárez, J. Sertucha, P. Larrañaga, and J. Lacaze: Metall. Mater. Trans. A, 2016, vol. 47A, pp. 2744-53.

16. E. Huerta and V. Popovski: AFS Cast Iron Inoculation Conference, Schaumburg, USA, 2005.

17. G. Bylund, H. Bark, B. Fredrikson, and T. Thoren: AFS Trans., 1975 , vol. 83, pp. 385-92.

18. C.R. Loper, Jr, R.W. Heine, C.C. Wang, and L. Janowski: AFS Trans., 1977, vol. 84, pp. 203-14.

19. A. SheikhAbdolhossein and M. Nili-Ahmadabadi: Int. J. Cast Met. Res., 2005, vol. 18, pp. 295-300.

20. S. Kim, S.L. Cockcroft, and A.M. Omran: J. Alloys Compd., 2009, vol. 476, pp. $728-32$

21. X.J. Sun, Y.X. Li, and X. Chen: J. Mater. Sci. Eng. A, 2007, vol. 466, pp. 1-8.

22. R. Lora and A. Diószegi: Metall. Mater. Trans. A, 2012, vol. 43, pp. $5165-72$

23. J.C. Hernando and A. Diószegi: Advances in the Science and Engineering of Casting Solidification, Springer, 2016, pp. 295-302.

24. J.C. Hernando, E. Ghassemali, and A. Diószegi: Mater. Charact., 2017, vol. 131, pp. 492-99.

25. G.F. Vander Voort: Metallography, Principles and Practice, McGraw-Hill, New York, 2007, p. 131

26. S.C. Murcia, E.A. Ossa, and D.J. Celentano: Metall. Mater. Trans. B, 2014, vol. 45, pp. 707-18.

27. R. Ruxanda and D.M. Stefanescu: Int. J. Cast Met. Res., 2002, vol. 14 , pp. 207-16.

28. K.M. Pedersen and N.S. Tiedje: Mater. Charact., 2008, vol. 59, pp. 1111-21.

29. ISO: ISO 16112: Compacted (vermicular) graphite cast irons Classification, ISO, 2006.

30. ASTM: ASTM A247: Standard Test Method for Evaluating the Microstructure of Graphite in Iron Castings, ASTM, 2016.

31. ISO: ISO 945: Microstructure of cast irons. Part 1: Graphite classification by visual analysis, ISO, 2008.

32. X.J. Sun, Y.X. Li, and X. Chen: J. Mater. Process. Technol., 2008, vol. 200, pp. 471-80.

33. A. Diószegi and I.L. Svensson: J. Mater. Sci. Eng. A, 2005, vols. 413-414, pp. 474-79.

34. D.M. Stefanescu: Int. J. Metalcast., 2015, vol. 9, pp. 7-22.

35. SinterCast, Process Control for the Reliable High Volume Production of Compacted Graphite Iron, (SinterCast, 2014). http://sintercast.com/library/technical-publications. Accessed 22 August 2017. 